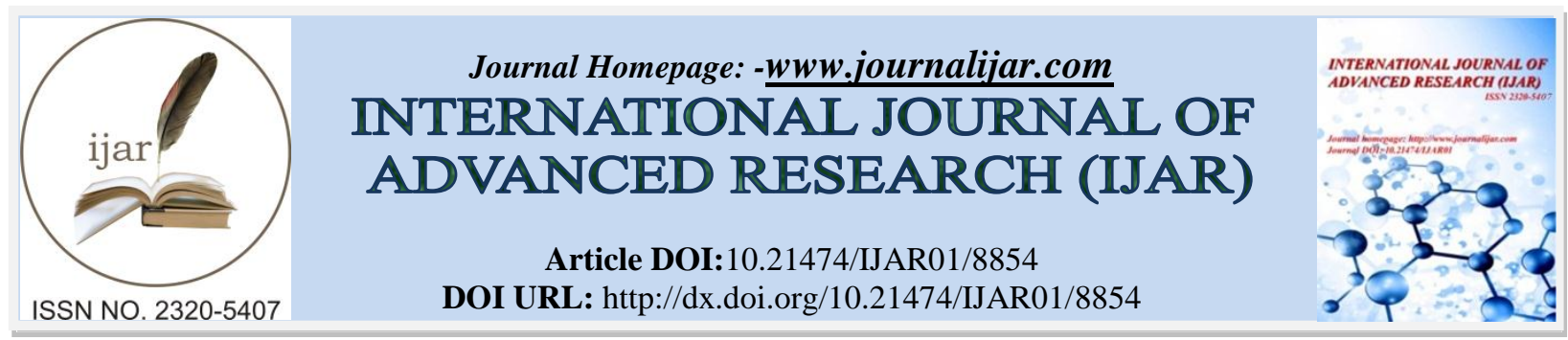

RESEARCH ARTICLE

\title{
A STUDY OF SERUM TSH AND CORTISOL LEVELS IN PREECLAMPSIA.
}

\section{Dr.Tarique aziz ${ }^{1}$ and Dr.G.G Kaushik ${ }^{2}$.}

1. Senior Demonstrator, Department of Biochemistry, J.L.N Medical College, Ajmer.

2. Senior Professor \& Head, Department of Biochemistry, J.L.N Medical College, Ajmer.

\section{Manuscript Info}

Manuscript History

Received: 10 February 2019

Published: April 2019
Final Accepted: 12 March 2019

\section{Abstract}

Aim: The study was carried out to estimate TSH and Cortisol level in preeclamptic women as compare to normotensive women.

Material and Methods: The present study has been conducted on 100 preeclamptic primigravidae in their trimester of pregnancy attending O.P.D of janana hospital, J.L.N Medical college Ajmer.

50 healthy primigravidae of similar age group were included in the study, as the control group.

Results: In this study we observed that out of 100 patients of preeclampsia in which 82 patients were of mild preeclampsia and 18 patients were of severe preeclampsia. There was significant decrease in level of cortisol in patients of mild and severe preeclampsia. Decrease in level of cortisol was more in severe preeclamptics as compared to mild preeclamptic patients. There was significant increase in level of TSH in mild preeclampsia whereas more increase in severe preeclampsia.

Conclusion: In this present study of 100 patients we concluded that from the results all these parameters play an important role in preeclampsia hence the measurement of TSH and cortisol activity may be used in early diagnosis and management of patients of preeclampsia. This can also be useful in assessing the severity of preeclampsia.

Copy Right, IJAR, 2019,. All rights reserved.

\section{Introduction:-}

Pregnancy is a physiological state associated with many alterations in metabolic, biochemical, physiological, haematological and immunological processes. If these changes are exaggerated, they can lead to complications during pregnancy. Pregnancy induced hypertention presents with new onset hypertentation and proteinuria after 20 weeks of gestation. Hypertensive disorders are the most common medical complications occuring during pregnancy. Pregnancy induced hypertension was reported with the incidence of about $10 \%$ of first pregnancy and $20 \%$ to $25 \%$ of previous pregnancy. The incidence of pregnancy Induced Hypertention (PIH) varies among different hospitals, regions and countries.

According to WHO's World Health Report 1998, Preeclampsia is defined as " the development of hypertention (>140/90 mm of $\mathrm{Hg}$ ) after 20 weeks of pregnancy in a woman with proteinuria associated with or without edema having no previous history of hypertention".

Corresponding Author:-Dr.Tarique aziz.

Address:-Departments of biochemistry, J L N Medical college, Ajmer. 
Preeclampsia stands out among the hypertensive disorder for its impact on maternal and neonatal health. It is one of the leading causes of maternal and perinatal mortality and morbidity

Pregnancy is usually associated with mild hypothyroidism. Woman complicated with preeclampsia have high incidence of hypothyroidism that might correlates with the severity of preeclampsia.

During pregnancy, there is an increased thyroid demand and increased iodine uptake and synthesis of thyroid hormones. Even though there is a state of hypothyroxinemia in normal pregnancy, it is more pronounced in preeclampsia.

Cortisol is a steroid hormone in the glucocorticoid class of hormones. It is produced in human by zona fasciculate of the adrenal cortex within the adrenal gland. Considerable evidence suggests that serum cortisol may play some important role in the normal pregnancy had a significant higher cortisol level then that of PIH patients. The lower maternal cortisol level of PIH patients became more significant with the severity of clinical symptoms of PIH.

Further studies are required to know the cause of high level of TSH and lower CORTISOL level, observed in pregnant woman with preeclampsia, which may help in management of pregnant woman at risk of pre eclamptic toxemia.

\section{Methodology:-}

Study Design: Case Cantrol Study

1. Cases- 100 preeclamptic primigravidae in third trimester of pregnancy

2. Controls- 50 healthy primigravidae in third trimester

3. Inpatients and outpatients of janana hospital, J.L.N Medical college Ajmer.

4. Estimation of serum cortisol and TSH by ELISA method.

\section{Inclusion criteria}

1. Preeclamptic primigravidae in third trimester-cases

2. Healthy primigravidae in third trimester-control

\section{Exclusion criteria}

1. Preeclamptic multigravidae

2. Healthy multigravidae

3. Known case of diabetes mellitus, renal disease and hypertension.

\section{Results and Discussion:-}

Level of cortisol in normal pregnancy and preeclampsia

\begin{tabular}{|l|l|l|}
\hline & Normal Pregnants $(\mathbf{n}=50)$ & Preeclamptic $(\mathbf{n}=\mathbf{1 0 0})$ \\
\hline $\begin{array}{l}\text { CORTISOL } \\
(\mathrm{ng} / \mathrm{mL})\end{array}$ & $67.1 \pm 14.7$ & $50.07 \pm 9.3$ \\
\hline
\end{tabular}

Comparison of Cortisol Level in Normal Pregnants and Mild Preeclamptics

\begin{tabular}{|l|l|l|l|}
\hline & Normal pregnant $(\mathbf{n = 5 0})$ & Mild preeclamptics $(\mathbf{n}=\mathbf{8 2})$ & p-value \\
\hline $\begin{array}{l}\text { CORTISOL } \\
(\mathrm{ng} / \mathrm{mL})\end{array}$ & $67.1 \pm 14.7$ & $42.08 \pm 7.26$ & $<0.0001$ \\
\hline
\end{tabular}

Comparison of Cortisol Level in Normal Pregnants and Severe Preeclamptics

\begin{tabular}{|l|l|l|l|}
\hline & Normal pregnant $(\mathbf{n}=50)$ & Severe Preeclamptics $(\mathbf{n}=\mathbf{1 8})$ & p-value \\
\hline $\begin{array}{l}\text { CORTISOL } \\
(\mathrm{ng} / \mathrm{mL})\end{array}$ & $67.1 \pm 14.7$ & $33.8 \pm 7.2$ & $<0.0001$ \\
\hline
\end{tabular}

Level of TSH in Normal Pregnancy and Preeclampsia

\begin{tabular}{|l|l|l|}
\hline & Normal pregnant $(\mathbf{n}=\mathbf{5 0})$ & Preeclamptic $(\mathbf{n}=\mathbf{1 0 0})$ \\
\hline TSH (mIU/L) & $3.05 \pm 1.06$ & $4.70 \pm 2.55$ \\
\hline
\end{tabular}

Comparison of TSH in Normal Pregnancy and Mild Preeclampsia

\begin{tabular}{|c|c|}
\hline Normal pregnant $(n=50)$ & preeclamptic \\
\hline
\end{tabular}




\begin{tabular}{|l|l|l|l|}
\hline & & $(\mathbf{n = 8 2})$ & \\
\hline TSH (mIU/L) & $3.05 \pm 1.06$ & $5.95 \pm 0.60$ & $<0.0001$ \\
\hline
\end{tabular}

Comparison of TSH in Normal Pregnancy and Severe Preeclampsia

\begin{tabular}{|l|l|l|l|}
\hline & Normal pregnant $(\mathbf{n = 5 0})$ & $\begin{array}{l}\text { Severe preeclamptic } \\
(\mathbf{n = 1 8})\end{array}$ & p-value \\
\hline TSH (mIU/L) & $3.05 \pm 1.06$ & $8.95 \pm 1.42$ & $<0.0001$ \\
\hline
\end{tabular}

The mean value $( \pm \mathrm{SD})$ of cortisol in normal pregnancy was $67.1 \pm 14.7 \mathrm{ng} / \mathrm{ml}$. In preeclampsia mean cortisol was $50.07 \pm 9.3 \mathrm{ng} / \mathrm{ml}$. Therefore mean level of cortisol was lower in the preeclamptic subjects than in normotensive group.

Mean value $( \pm \mathrm{SD})$ of cortisol in normal pregnant women was $67.1 \pm 14.7 \mathrm{ng} / \mathrm{ml}$. In mild preeclampsia mean was $42.08 \pm 7.26 \mathrm{ng} / \mathrm{ml}$. In severe preeclampsia mean was $33.80 \pm 7.2 \mathrm{ng} / \mathrm{ml}$. Thus there was highly significant difference between normal pregnant and severe preeclamptic subjects.

Pregnancy induces physiologic changes which coupled with emotional stress and challenges, contribute to changes in hormonal and biochemical status of pregnant women, especially, electrolytes imbalance and depletion of macronutrients. The associated increase in serum cortisol is a possible indicator of emotional stress and physiological challenges in pregnancy. The concurrent increase in progesterone and prolactin are compensating mechanism in response to these challenges, particularly an increase in cortisol concentration. While homeostatic mechanism corrected the electrolytes imbalance, most of the biochemical and hormonal changes which are more pronounced at the first and second trimester extends to last weeks of pregnancy. This study shows that cortisol may be playing a central role in the biochemical changes that were earlier reported in pregnancy and those that are peculiar to this study.

Mean value $( \pm \mathrm{SD})$ of TSH in normal pregnant was $3.05 \pm 1.06 \mathrm{mlU} / \mathrm{L}$. Mean value $( \pm \mathrm{SD})$ of TSH in pre eclamptic women was $4.70 \pm 2.55 \mathrm{mlU} / \mathrm{L}$. Therefore mean level of $\mathrm{TSH}$ was higher in the preeclamptic subjects than in normotensive groups.

Mean value $( \pm \mathrm{SD})$ of TSH in normal pregnancy was $3.05 \pm 1.06 \mathrm{mlU} / \mathrm{L}$. Mean value $( \pm \mathrm{SD})$ of mild preeclamptic was $5.95 \pm 0.60 \mathrm{mlU} / \mathrm{L}$. In severe preeclamptic mean value $( \pm \mathrm{SD})$ was $8.95 \pm 1.42 \mathrm{mlU} / \mathrm{L}$. There was significantly higher level of TSH in both mild and severe preeclamptic subjects than in control subjects.

Increase in serum binding forms of thyroid hormone may be due to the marked increase in the circulating level of the major $\mathrm{T}_{4}$ binding protein, thyroid-binding globulin. This globulin is induced by high estrogen levels in pregnancy, the stimulatory effect of serum hcG of placental origin, increased metabolic demand and mental stress may play increase overall thyroid activity and elevate thyroid hormone levels.

\section{Conclusion:-}

1. The present study was conducted on 100 patients of pre eclampsia in which 82 patients were of mild preeclampsia and 18 patients were of severe preeclampsia. The results were compared with 50 normotensive age matched subjects.

2. There was significant decrease in level of cortisol in patients of mild and severe preeclampsia. Decrease in level of cortisol was more in severe preeclamptics as compared to mild preeclamptic patients.

3. There was significant increase in level of TSH in mild and severe preeclampsia.

4. There was more increase in level of TSH in severe preeclamptic patients as compared to mild preeclamptic patients.

5. The study shows that in preeclampsia the activity of TSH is elevated whereas cortisol level is decreased.

6. Because of its reliability, easy accessibility and affordability, it's hereby suggested that measurement of TSH and cortisol activity may be used in early diagnosis and management of patients of preeclampsia.

7. This can also be useful in assessing the severity of preeclampsia. 


\section{References:-}

1. Abalovich M, Gutierrex S, Alcaraz G, Maccallini G, Garcia A, Levalle O. Overt and subclinical hypothyroidism complicating pregnancy. Thyroid $2002 ; 12: 63-68$

2. Basbug M, Aygen E, Tayyar M, Tutus A, KayaE, Oktem O. Correlation between maternal thyroid function tests and endothelium in pre eclampsia. Obstet Gynecol 1999;94:551-555

3. Bodnar LM, Ness RB, Markovic N, Roberts JM. The risk of preeclampsia rises with increasing pre pregnancy body mass index.Ann Epidemiol 2005; 15:475-482

4. Bowen CB, Qiu C . Oxidative stress in preeclampsia. Acta Obstet Gynecol scand 2001;80:719-725

5. Carey b m, DasheJS, wells CE, McIntire DD, Byrd EW, Leveno KJ. Subclinical hypothyroidism and pregnancy outcomes. Obstet Gynecol 2005;105:239-245

6. Divya sardana, Smiti nanda, Simmi kharb. Thyroid hormones in pregnancy and pre eclampsia. Turkish journal gynecol association 2009;10:168-171

7. Dhananjaya BS, kumaran DS, venkatesh G, Murthy N, Shashiraj H. Thyroid stimulating hormone level as a possible indicator of pre eclampsia. Journal of clinical and diagnostic research 2011;5:1542-1543

8. Franklyn J A. The management of hyperthyroidism. N Engl. J. Med 1994;330:1731-17

9. Hou S.Pregnancy in chronic renal insufficiency and end stage renal disease.Am J Kidney Dis. Feb 1999;33:235-252

10. Khaliq F, Singhal, Z Arshad and M M Hossain. Thyroid functions in pre eclampsia and its correlation with maternal age, severity of blood pressure and serum albumin. Indian journal Physio Pharmacol 1999; 43: 193-198

11. Kopelman J.J and Levitz M. Plasma cortisol level and cortisol binding in normal and pre eclamptic pregnancies. American Journal Obstet. Gynec.1970; 108:925-930

12. Kumar A, Ghosh B. K and Murthy N S. Maternal thyroid hormonal status in pre eclampsia. Indian Journal med. Sci 2005;59:57-63

13. Kaya E, Sahin y, Ozkececi, Z and Pasaoglu, H. Relation between birth weight and thyroid function in pre eclampsiaeclampsia. Gynaecol.Obstet. Invest.37.1994;30-33

14. Kaya E, Sahin Y, Ozkceci Z, Pasaoglu H. Relation between birth weight and thyroid function in preeclampsia. Gynecol Obstet Invest 1994;37:30-33

15. Kaplan M.M. Management of women on thyroxine therapy during pregnancy. Endocr. Pract. 1996; 2:281.

16. Lao TT, Chin RK, Swaminathan R, Lam YM. Maternal thyroid hormones and outcome of preeclamptic pregnancies. An Int. Journal Obstet Gynaecol 1990;97:71-74

17. Larijini B, Marsoosi v, Aghakhani S, Moradi A and Hashemipour S. Thyroid hormone alteration in pre eclamptic woman. Gynecol. Endocrinol 2004; 18:97-100

18. Lafayette RA, Druzin M, Sibley R. Nature of glomerular dysfunction in pre eclampsia. Kidney International 1998;54:1240-1249

19. Merchant SJ and Davidge ST. The role of matrix metalloproteinases in vascular function: implication for normal pregnancy and pre eclampsia. Br Journal obstet Gynecol 2004;111:931-939

20. Manjunatha S. Thyroid dysfunction in pregnancy and pre eclampsia. Scholars journal of applied medical sciences 2014;2:3297-3299

21. Muzammil S, Khayyam UK, Siddiqui N ali. Serum protein ratio in normal and preeclamptic women of primiparous and multiparous in relation to age. International Journal Basic Appl Med Sci 2014;4:331-335

22. Nobuaki Furuhashi, Hideaki Kono. Serum cortisol levels in pregnancy Induced Hypertension Patients. Tohoku J exp. Med, 1986; 149:21-24

23. Palanisamy Pasupati, $\mathrm{P}$ Rani. Evaluation of serum lipids and Thyroid Hormone changes in non pregnant, pregnant and pre eclampsia Woman. Thyroid science 2009;10:1-6

24. Pruyn S c, Phelan j.p and Buchanan G. C. Long term propranolol therapy in pregnancy. Maternal and fetal outcome. Assoc. Med. Journal Obstet Gynecol. 1979;135:485-489

25. Qublan HS, Al-kaisi IJ, Hindawi IM, Hiasat MS, Awamleh I. Severe preeclampsia and maternal thyroid function. Journal Obstet Gynecol. 2003; 23:244-246

26. Rahul R. chaudhary. A study of thyroid profile and serum albumin in preeclampsia woman. International $\mathrm{J}$ cur res rev 2016;8:23-24

27. Rajappa M, Sen SK. Evaluation of Thyroid hormone status after acute mayocardial infarction in South Indians. Biomedical Research 2005;16:15-18

28. Rahman M H., Chowdhury, M.A and Alam, M.T. Serum thyroxine and triiodothyronine levels in normal pregnancy and preeclampsia.TAJ 2007;20:06-10

29. Robert JM, Hubel CA. Recent insight into the pathogenesis of preeclampsia.Placenta 2002;23:359-372

30. Sonal sogani, vandana verma, purnima dev sarkar. Estimation of thyroid hormones levels in preeclamptic pregnant woman; an early predictor of the disease. Al amen j med science 2015; 8:266-270. 